\title{
Are Cloth Tarpaulin Mounted Nets Effective for Discard Reduction in Trammel Nets?
}

\author{
Ahmet Raif Eryaşar ${ }^{1, *} \mathbb{1}$, Yusuf Ceylan², Hüseyin Özbilgin ${ }^{3}$, Adem Sezai Bozaoğlu $^{4}$ \\ ${ }^{1}$ Recep Tayyip Erdogan University, Vocational School of Technical Sciences, Underwater Technology Program, Rize, \\ Turkey \\ ${ }^{2}$ Recep Tayyip Erdogan University, Faculty of Fisheries, Rize, Turkey \\ ${ }^{3}$ Mersin University, Faculty of Fisheries, Mersin, Turkey \\ ${ }^{4}$ Van Yuzuncu YIl University, Faculty of Fisheries, Van, Turkey
}

\section{Article History}

Received 14 May 2020

Accepted 26 November 2020

First Online 30 November 2020

\section{Corresponding Author \\ Tel.: +904642280022-2180 \\ E-mail: \\ ahmet.eryasar@erdogan.edu.tr}

\section{Keywords}

Black Sea

Red mullet

Entangling net

By-catch

\begin{abstract}
Discarding is a significant problem due to net damage and labour loss in trammel net fisheries. In this study, the effects of 15,25 , and $35 \mathrm{~cm}$ high cloth tarpaulin rigged between the lead line and the net were investigated in reducing the discard amount of trammel nets for red mullet (Mullus barbatus) in the south-eastern Black Sea. During the study, twenty fishing trips were carried out on-board a commercial vessel between May 11 and June 20, 2018. Results showed that there were no significant differences in the amount of discards between the commercial and experimental nets $(P>0.05)$ However, cloth tarpaulin mounted nets (CTMN) were found to be significantly successful to reduce the amount of shore crab (Liocarcinus depurator) and the veined rapa whelk (Rapana venosa) $(\mathrm{P}<0.05)$. Although it is insignificant, a decline of capture was also observed in the amount of target species in CTMN compared to the commercial net (CN). Finally, the advantages and concerns of this gear modification, and potential reasons for the reduction of target and discard species are discussed.
\end{abstract}

\section{Introduction}

Discarding is one of the most important issues for fisheries management since it is considered a waste of resources, a source of uncertainty for fisheries scientists and decision-makers, as well as a factor affecting biodiversity and community structure (Tsagarakis et al., 2014). The annual fishery discard amount has been estimated to be about 230.000 tonnes for the Mediterranean, and 45.000 tonnes for the Black Sea (FAO, 2018). Related studies on discards for small-scale fisheries (i.e. trammel and gillnets) are relatively scarce for the Mediterranean and the Black Sea, but limited data report a discard ratio lower than $10 \%$ for the Mediterranean and 15\% for the Black Sea (FAO, 2018). However, Tsagarakis et al. (2014) reported that discard rates of trammel nets may exceed $40 \%$ in some fishing areas of the Mediterranean.
Red mullet trammel nets are one of the most widely used fishing gears in the eastern Black Sea, but information is limited on their catch and discard composition. Kalaycı and Yeşilçicek (2014) demonstrated that 27 species were caught by red mullet trammel nets, and $77 \%$ of the total catch was composed of discard species for the region. They also reported that shore crab (Liocarcinus depurator) and rapa whelk (Rapana venosa) were the most discarded species.

In the eastern Black Sea Region where trawling is forbidden (Anonymous, 2016), trammel nets are mostly used to catch demersal species such as red mullet (Mullus barbatus) and whiting (Merlangius merlangus). The most productive season is summer for red mullet fishing in the region. However, the capture of discard species along with the target species constitutes a significant problem for small-scale fishers in this season. In this period, there are serious increases in discard rate 
due to the interaction of unwanted species such as crabs (Brachyura) and the veined rapa whelk (Rapana venosa) in the shallow waters (Kalaycı \& Yeşilçiçek, 2014). These species cause damage to the captured fish and nets, as well as increasing the labour to clean them from the net. Besides, to ease the cleaning of the nets, these species are either crushed by fishermen or exposed to serious injuries, and they are thrown back to the sea, mostly dead or wounded.

There are several studies on reduction of the discards in the trammel nets used in the Mediterranean and Black Sea (Aksu, 2006; Metin et al., 2009; Bozaoğlu, 2012; Aydın et al., 2013a; Gökçe et al., 2016; Catanese et al., 2018; Sartor et al., 2018). These studies demonstrated that the use of a guarding net between the lead line and the net reduces the amount of discarded catch. However, reduction in catch amount of target species with the use of guarding net makes it difficult to prefer by fishermen when compared to the conventional nets.

For a profitable red mullet trammel net fishery, the development of gears that reduce the discard rate as well as target catch losses is required. The cloth tarpaulin rigged between the lead line and the net may allow reducing the both discard rate and target catch losses. The idea of this modification was based on the assumption that the red mullet which is captured by commercial fisherman between sunset and sunrise would perceive the cloth tarpaulin as a barrier and then rise and get entangled in the net. Besides, it would prevent the entanglement of crabs and whelk species due to their inability to climb up it. In this study, cloth tarpaulin mounted nets were compared with commercial red mullet nets in order to reduce the discarded catch while minimizing the catch loss of target species.

\section{Materials \& Methods}

Experiments were carried out between May 11 and June 20, 2018 in Rize province of the south-eastern Black Sea Region. The commercial boat "Orkan 53" (9 m overall length with 170 HP engine power) was used in a total of 20 fishing trials. Sea trials were carried out under commercial conditions. The nets were deployed between 7 and $18 \mathrm{~m}$ in depth before dusk, and they were hauled back to the surface after sunset. Mean soaking time was approximately 3 hours.

During the study, the cloth tarpaulin rigged nets were compared with commercial ones. The technical specification and illustration of commercial net are displayed in Figure 1. The nets used were made with hanging ratios of 0.50 on the float line and 0.51 on the lead line. In the south-eastern Black Sea Region, one panel of commercial trammel net is rigged as $100 \mathrm{~m}$ in length. Generally, 5 panels of net are used in the region as the bottom structure of fishing ground is a limiting factor for amount of the nets used.

For the experimental nets, cloth tarpaulins of 15 , 25 and $35 \mathrm{~cm}$ height are rigged between the bottom part of the commercial net and the lead line (Figure 2). The cloth tarpaulin was made of cotton material and was $145 \mathrm{~g}$ per $\mathrm{m}^{2}$. The height of the cloth tarpaulin was determined considering the rising behaviour $(2.40 \mathrm{~m}$ in length and $40 \mathrm{~cm}$ in depth) of the shore crabs (Liocarcinus depurator) in front of beam trawls which was reported by Eryaşar (2017).

While the cloth tarpaulins were being rigged, the depths of the commercial nets were not changed. Each of the cloth tarpaulin mounted net is rigged with $20 \%$ more float and lead when compared with the commercial net for taking appropriate position underwater. The upper part of the cloth tarpaulins is

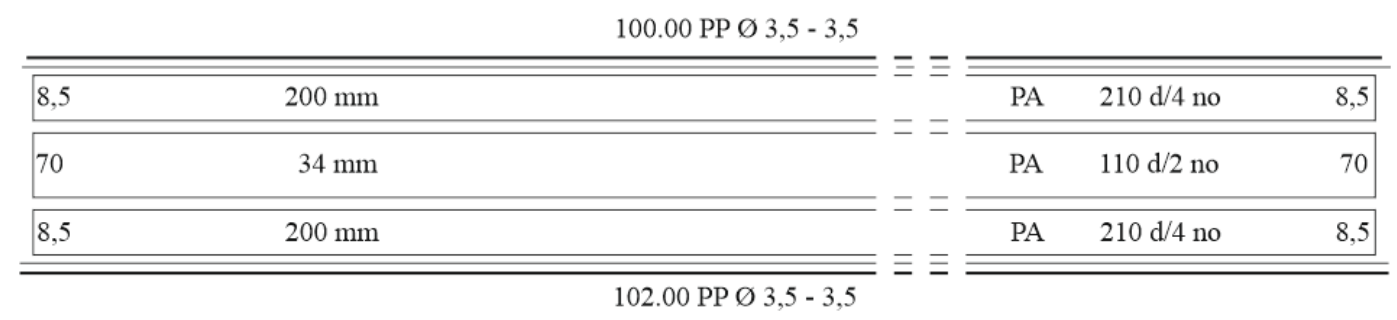

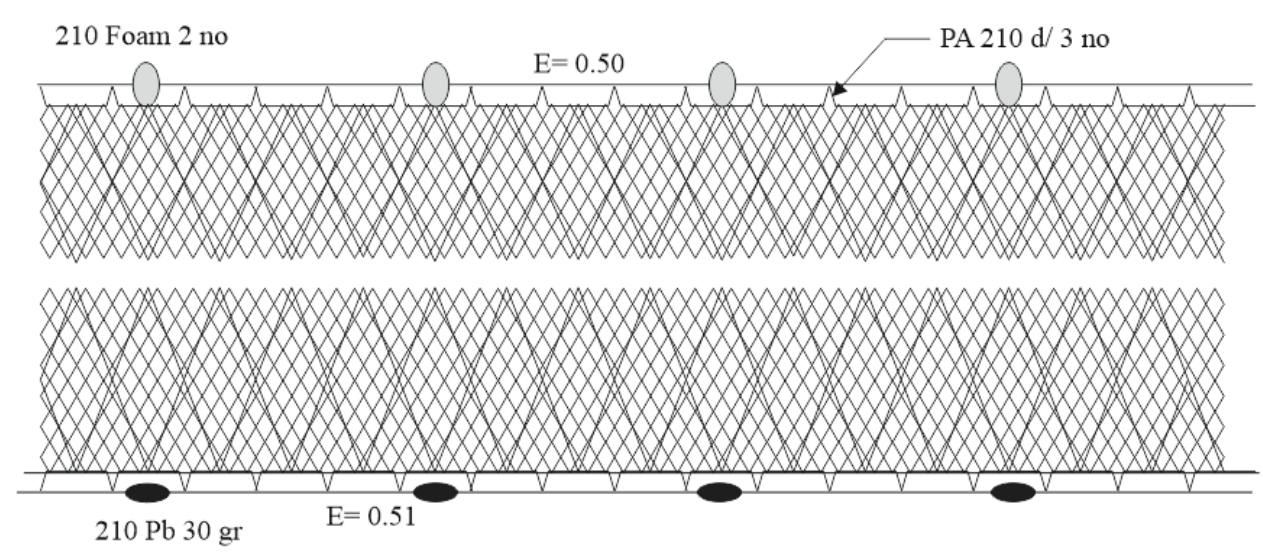

Figure 1. Technical specification and illustration of commercial net. 
sewed to the lower part of the commercial nets with the help of a sewing machine. For the lower part, the lead line was sewed to the bottom of the cloth tarpaulins. Due to the fact that fish are less likely to approach to objects with high contrast (Glass et al., 1993), it was thought that white colour may shine on the ground and cause the fish to stay away from the net, the colour of the cloth tarpaulins was chosen as black for minimizing underwater contrast of the gear.
For observations of the nets, diver and underwater action cameras were used to understand if there was a problem with tested nets during the study. For observations with action cameras, no light source was used with four cameras (GoPro 4 Silver) mounted in pairs on $8 \mathrm{~kg}$ of stones and positioned in front of the tested nets. When the video record was analysed, no problem was observed in the standing of the nets underwater (Figure 3). Besides, no problem was

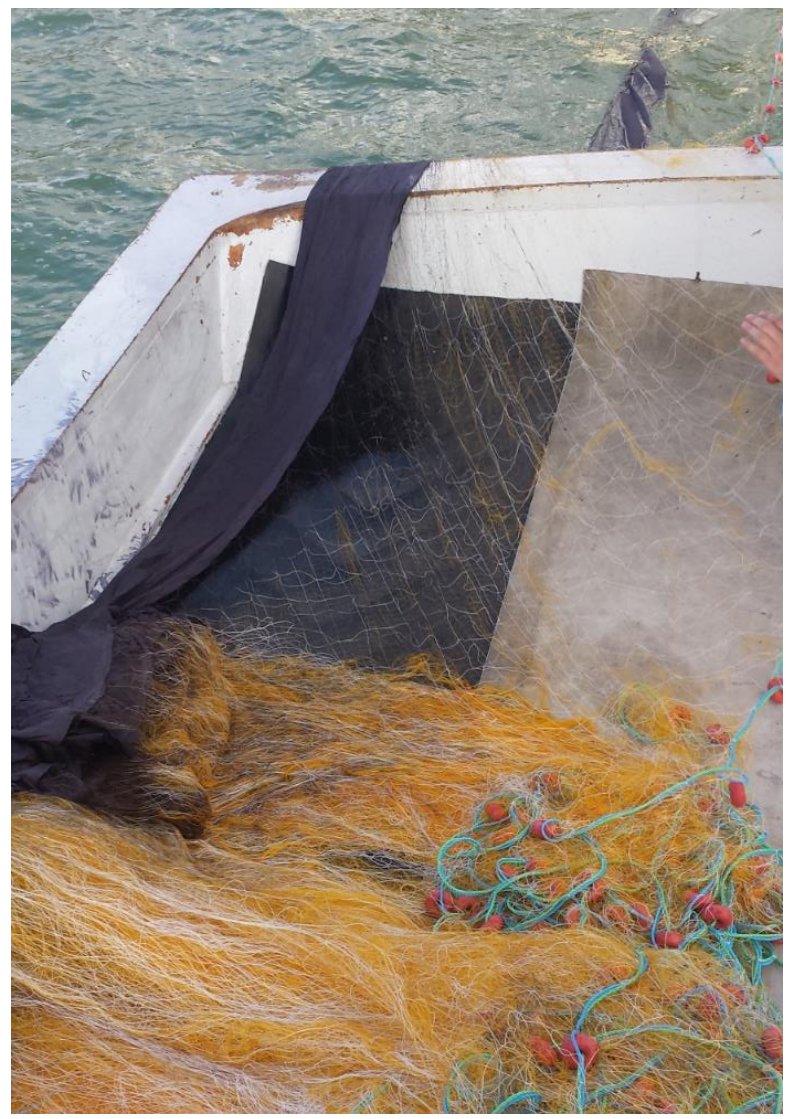

Figure 2. Cloth tarpaulin mounted nets.

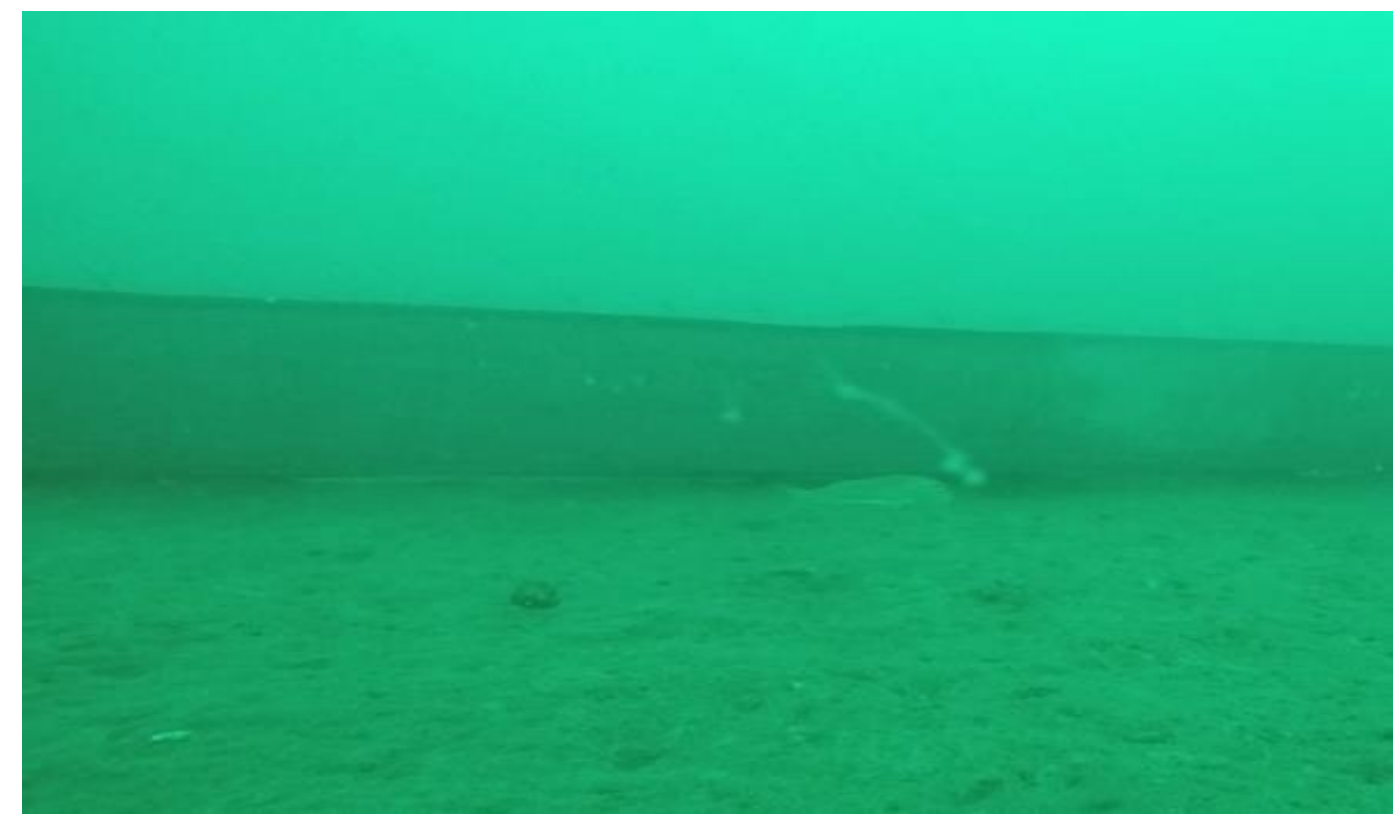

Figure 3. Standing of the cloth tarpaulin mounted nets underwater. 
experienced while shooting and hauling the nets, and fishers were able to operate them easily. However, cloth tarpaulin should be wetted before setting. Otherwise, cloth tarpaulin mounted nets can remain floating for a while on the surface. This situation was seen in a shooting before the beginning of trials.

During the study period, taking the status of the study area into account, one unit $(100 \mathrm{~m})$ of each type of trammel net was used for each operation. A total of 4 units was set in juxtaposition with a $1 \mathrm{~m}$ distance between all tested nets. The nets are added to each other as commercial, 15, 25 and $35 \mathrm{~cm}$ high cloth tarpaulin mounted nets from the first operation. Then, the order of the nets was changed randomly at every opportunity. At the end of the operation, the fishers separated the fish and crustacean species captured in each net, and then the number and weight measurement of each species were recorded by researchers. The total length of fish was measured using a fish measuring board. Veined rapa whelk and crab species were measured by using $0.01 \mathrm{~mm}$ precision electronic calliper and the length from the spinal canal to the apex of the veined rapa whelk and carapace length of crabs were taken into consideration in length measurements.

Discard rates of commercial and experimental nets were obtained by dividing the total catch amount of the discarded species by the total amount of catch. Catch per unit effort (CPUE) values of commercial and experimental nets were calculated for each species in each operation. CPUE was calculated with the formula given below.

$$
\text { CPUE }=\frac{\mathrm{C}}{\mathrm{H}}
$$

In the formula, "C" is the catch amount (number or weight) of a captured species, " $\mathrm{H}$ " is the soak time (hour) of the tested gear.

The Kruskal-Wallis test was used to determine whether there was a statistically significant difference in the catch amounts (in terms of number) between tested nets. Multiple comparisons were performed using the Nemeyni test. PMCMR package of $\mathrm{R}$ was used to run this test. In the statistical comparison of the length distributions of the captured species for commercial and experimental nets, Kolmogorov-Simirnov test was used. Statistical analysis was performed in the R 3.6 statistical environment (R Core Team, 2019).

\section{Results}

The video recordings showed that there was no problem related to the standing of cloth tarpaulin mounted nets (CTMN). However, it was seen that CTMN was moving backward or forward in line with the direction of the bottom current.

Total catch was composed of 3013 individuals belonging to 27 species from five classes (Gastropada, Bivalvia, Malacostraca, Elasmobranchii, Actinopterygii).
During the study, the target species was only red mullet; all other species were discarded by commercial fishermen. On the other hand, some discarded species had a commercial value (e.g. Merlangius merlangus, Solea solea, etc.) but they were not sold due to insufficient amounts.

At the end of the sea trials, the discards of the catch (in terms of number) with the commercial, 15, 25 and $35 \mathrm{~cm}$ high cloth tarpaulin mounted nets were calculated as $83 \%, 78 \%, 73 \%, 81 \%$, respectively. In terms of weight, discard ratios were found as $78 \%, 80 \%, \% 74$, and $81 \%$, respectively. There were no statistically significant differences in the amount of discards (in terms of number and weight) between the tested nets $(P>0.05)$. The percentage reduction in the amount of target species (in terms of number) captured by the 15 , 25 and 35 high cloth tarpaulin mounted nets (CTMN) when compared to the commercial net (CN) was found as $36 \%, 17 \%$ and $49 \%$, respectively. In term of weight, these reductions were calculated as $44 \%, 21 \%$, and $51 \%$, respectively. Although there was a decrease in the catch number and weight, there was no statistically significant difference between nets ( $P>0.05)$.

According to Table 1 , the most captured species with tested nets were black scorpion fish (Scorpaena porcus), red mullet (Mullus barbatus), the veined rapa whelk (Rapana venosa), stargazer (Uranoscopus scaber), and shore crab (Liocarcinus depurator), respectively. Table 2 shows the total weight, the mean CPUE (in terms of number and weight) and mean length values of target and most discarded species.

The highest mean CPUE for red mullet was with the commercial net (Table 2). In terms of catch number and weight, no statistically significant difference was found between the tested nets ( $P>0.05)$. Figure 4 shows the length-frequency distributions of red mullet captured by the tested nets. It was observed that the nets mostly caught individuals in the $14,14.5$ and $15 \mathrm{~cm}$ length groups. In addition, there were significant differences in length distributions between experimental and commercial nets $(\mathrm{P}<0.05)$.

For black scorpion fish, the highest CPUE was seen in the $25 \mathrm{~cm}$ CTMN (Table 2). The differences in catch amount (in terms of number and weight) between tested nets were not statistically significant $(P>0.05)$. When the length distributions of the specimens caught by the tested nets were examined, it was seen that most of the catches were in the length groups between 12.5 and $16 \mathrm{~cm}$ (Figure 5A). Furthermore, there were no significant differences in length distributions between tested nets $(P>0.05)$.

Stargazer was mostly caught with the $35 \mathrm{~cm}$ CTMN (Table 2). There were no statistically significant differences between the tested nets in terms of the catch amount (in terms of number and weight) of this species $(P>0.05)$. Figure 5B shows that the tested nets mostly caught fish in length groups between 11 and 14.5 $\mathrm{cm}$. Besides, there were no significant differences in length distributions among tested nets $(P>0.05)$. 
Veined rapa whelk was mostly caught with the $\mathrm{CN}$ (Table 2). In terms of catch number and weight, statistically significant difference was found in the catch amount between tested nets $(P<0.05)$. Nemeyni Pairwise Multiple Comparison showed significant differences in catch number and weight between $\mathrm{CN}$ and each CTMN $(P<0.05)$. The length groups between 30 and $35 \mathrm{~mm}$ were mostly caught with the tested nets (Figure 5C). There were no significant differences among tested nets in terms of length distributions $(P>0.05)$.

For the shore crab, the highest CPUE was with the CN (Table 2). In terms of catch number and weight, there was a statistically significant difference in the catch amount of the shore crab between tested nets. $(P<0.05)$. Nemeyni test showed significant differences in catch weight between $\mathrm{CN}$ and each of the CTMN $(\mathrm{P}<0.05)$. For catch number, significant differences were found between $\mathrm{CN}$ and 25 and $35 \mathrm{~cm}$ CTMN $(P<0.05)$. When the length distributions of the individuals caught by the tested nets were examined, it was seen that most of the catches were of the $30 \mathrm{~mm}$ size class (Figure 5D). There were no significant differences in length distributions among tested nets $(P>0.05)$.

\section{Discussion}

To the best of our knowledge, this is the first study in which cloth tarpaulin mounted nets are tested to reduce the discard of trammel nets for red mullet fishery. To avoid the floatation of cloth tarpaulin mounted nets in commercial fishing operations, they must be saturated with sea water beforehand. During operations, mentioned problem was not observed while the nets were set on the bottom because they were wet. However, it is important to note that nets should not remain wet for long periods due to degradation of the cloth tarpaulin.

The catch amount of discards was significantly reduced by use of guarding net (Metin et al., 2009; Gökçe et al., 2016) and norsel (Godoy et al., 2003; Eayrs \& Salerno, 2008) which were mounted between the nets and the lead line. The present study shows that CTMN is not successful enough to reduce the total amount of discards when compared with $\mathrm{CN}$ (Table 1). The difference between this study and the abovementioned studies in the context of reducing the amount of discard is thought to be caused by the material used, the

Table 1. List of species and quantities captured by each net

\begin{tabular}{|c|c|c|c|c|c|c|}
\hline \multirow[b]{2}{*}{ Target Species } & \multirow[b]{2}{*}{ Group } & \multirow[b]{2}{*}{$\mathrm{CN}$} & \multicolumn{3}{|c|}{ Experimental Nets (CTMN) } & \multirow[b]{2}{*}{ Total Number } \\
\hline & & & $15 \mathrm{~cm}$ & $25 \mathrm{~cm}$ & $35 \mathrm{~cm}$ & \\
\hline Mullus barbatus & $\mathrm{APe}$ & 206 & 131 & 170 & 105 & 612 \\
\hline \multicolumn{7}{|l|}{ Discard Species } \\
\hline Scorpaena porcus & ASc & 166 & 149 & 188 & 133 & 636 \\
\hline Rapana venosa* & MG & 343 & 55 & 39 & 54 & 491 \\
\hline Uranoscopus scaber & $\mathrm{APe}$ & 140 & 114 & 95 & 138 & 487 \\
\hline Liocarcinus depurator * & $C D$ & 207 & 68 & 48 & 51 & 374 \\
\hline Solea solea & API & 88 & 48 & 45 & 40 & 221 \\
\hline Ophidion barbatum & AOp & 9 & 8 & 10 & 6 & 33 \\
\hline Gobius sp. & $\mathrm{APe}$ & 10 & 3 & 9 & 9 & 31 \\
\hline Trachurus mediterraneus & $\mathrm{APe}$ & 6 & 7 & 11 & 6 & 30 \\
\hline Trachinus draco & $\mathrm{APe}$ & 9 & 9 & 5 & 5 & 28 \\
\hline Arnoglossus kessleri & API & 5 & 1 & 5 & 2 & 13 \\
\hline Merlangius merlangus & AGa & 6 & 1 & 2 & 0 & 9 \\
\hline Eriphia verrucosa & $C D$ & 6 & 0 & 1 & 1 & 8 \\
\hline Labrus sp. & $\mathrm{APe}$ & 0 & 3 & 3 & 2 & 8 \\
\hline Diplodus annularis & $\mathrm{APe}$ & 0 & 2 & 2 & 2 & 6 \\
\hline Pachygrapsus marmoratus & $C D$ & 2 & 2 & 0 & 1 & 5 \\
\hline Spicara smaris & $\mathrm{APe}$ & 1 & 1 & 1 & 2 & 5 \\
\hline Callionymus pusillus & $\mathrm{APe}$ & 1 & 0 & 1 & 2 & 4 \\
\hline Raja clavata & ERa & 2 & 0 & 0 & 0 & 2 \\
\hline Anadara kagoshimensis & $\mathrm{MB}$ & 1 & 0 & 1 & 0 & 2 \\
\hline Diogenes pugilator & $C D$ & 1 & 1 & 0 & 0 & 2 \\
\hline Hippocampus sp. & ASy & 1 & 0 & 0 & 0 & 1 \\
\hline Syngnathus sp. & ASy & 1 & 0 & 0 & 0 & 1 \\
\hline Liocarcinus navigator & $\mathrm{CD}$ & 0 & 1 & 0 & 0 & 1 \\
\hline Tritia reticulata & MG & 0 & 0 & 1 & 0 & 1 \\
\hline Sprattus sprattus & $\mathrm{ACl}$ & 0 & 0 & 1 & 0 & 1 \\
\hline Xantho poressa & $C D$ & 0 & 1 & 0 & 0 & 1 \\
\hline
\end{tabular}

$\mathrm{ACl}=$ Actinopterygii: Clupeiformes, AGa Actinopterygii: Gadiformes, AOp Actinopterygii: Ophidiiformes, APe=Actinopterygii: Perciformes, API Actinopterygii: Pleuronectiformes, ASc=Actinopterygii: Scorpaeniformes, ASy = Actinopterygii: Syngnathiformes, CD=Crustacea: Decapoda, ERa Elasmobranchii: Rajiformes, MB = Mollusca: Bivalvia, MG=Mollusca: Gastropoda. Species that show statistically significant reduction in experimental nets are marked with an asterisk. (Total fishing effort was 70 hours). 
Table 2. Catch data of most discarded species for commercial and experimental nets

\begin{tabular}{|c|c|c|c|c|c|c|c|c|c|c|c|c|c|c|c|c|}
\hline \multicolumn{6}{|c|}{ Commercial Net } & \multicolumn{3}{|c|}{15 CTMN } & \multicolumn{5}{|c|}{25 CTMN } & \multicolumn{3}{|c|}{35 CTMN } \\
\hline & TW & CPUE W (SD) & CPUE N (SD) & ML (SD) & TW & CPUE W (SD) & CPUE N (SD) & ML (SD) & TW & CPUE W (SD) & CPUE N (SD) & ML (SD) & TW & CPUE W (SD) & CPUE N (SD) & $\mathrm{ML}(\mathrm{SD})$ \\
\hline RM & 7972 & $111.44(100.60)$ & $2.96(2.24)$ & $15.2(2.03)$ & 4457 & $67.97(49.89)$ & $2.02(1.46)$ & $14.7(2.28)$ & 6330 & 94.55 (76.17) & $2.57(1.72)$ & 14.9 (1.99) & 3892 & $60.19(49.42)$ & $1.63(1.26)$ & $14.7(2.10)$ \\
\hline BSP & 7854 & $111.16(165.76)$ & $2.41(3.91)$ & $13.6(2.04)$ & 8249 & $116.35(236.70)$ & $2.15(4.82)$ & $14.4(1.93)$ & 9597 & $139.51(285.57)$ & $2.78(6.00)$ & $13.9(1.88)$ & 6525 & $100.13(183.44)$ & $2.08(4.36)$ & $13.5(1.66)$ \\
\hline VRV & 5475 & 76.91 (77.79) & $4.76(6.21)$ & $3.87(1.30)$ & 891 & $12.59(19.02)$ & $0.77(1.43)$ & $3.85(1.34)$ & 594 & $8.91(12.08)$ & $0.57(0.82)$ & $3.90(1.18)$ & 705 & 8.89 (13.76) & $0.69(0.79)$ & $3.78(1.04)$ \\
\hline SG & 5457 & 81.82 (78.59) & $2.12(2.41)$ & $13.1(2.22)$ & 5340 & 83.39 (63.03) & $1.82(1.44)$ & $13.3(2.58)$ & 4500 & $69.12(94$ & $1.51(1.77)$ & $13.5(2.80)$ & 6072 & 99.69 & $2.30(2.44)$ & $13.3(2.66)$ \\
\hline SC & 1596 & $22.73(38.04)$ & $2.96(4.93)$ & $3.04(0.42)$ & 504 & 7.91 (10.41) & $1.06(1.45)$ & $3.00(0.49)$ & 406 & 6.17 (10.09) & $0.72(1.01)$ & $3.09(0.53)$ & 357 & 5.15 (11.80) & $0.74(1.43)$ & $3.02(0.50)$ \\
\hline
\end{tabular}

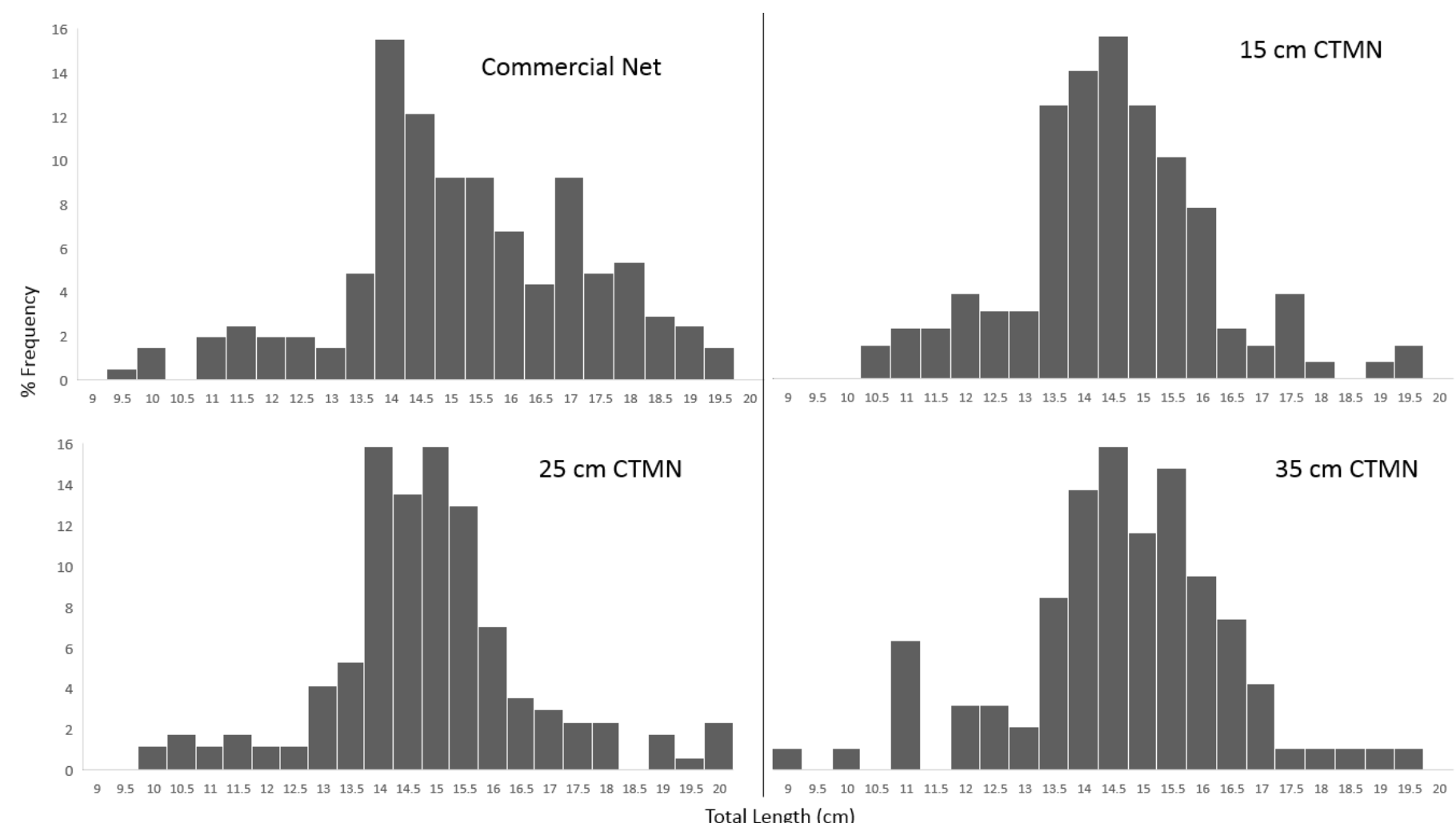

Figure 4. Length-frequency distributions of red mullet captured by tested nets. 

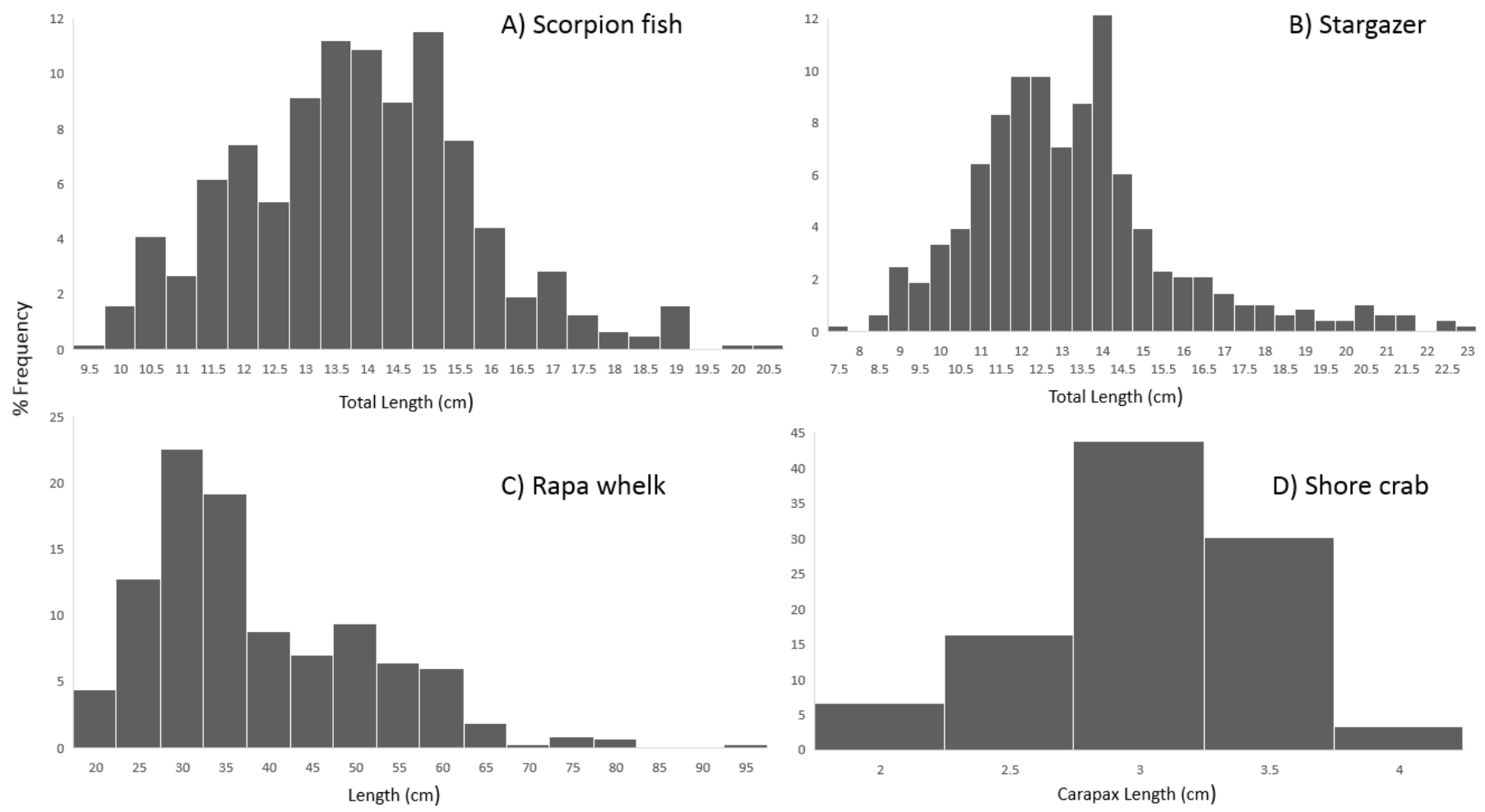

Figure 5. Length-frequency distributions of scorpion fish (A), stargazer (B), rapa whelk (C) and shore crab (D). 
working areas, the marine species living in these areas and the different behaviours of these species with regard the nets.

The video records showed that the bottom current in the region was influencing the posture of the CTMNs. It was found out that CTMNs tend to move backward or forward in direction of the bottom current. It is possible to claim that the stability of CTMN is affected more when compared with commercial ones and this situation may have affected the catch efficiency of the fishing gear. In addition, it was seen that the $35 \mathrm{~cm}$ CTMN, which stands upright in normal operation conditions, can lie on the ground at times when it starts to move forward or backward with the effect of currents. This situation makes the net lay down towards the bottom; thus, possibly leading the other living species climb onto the CTMN. This may explain why the $35 \mathrm{~cm}$ CTMN has caught more discard species. A similar finding was found in a study carried out by Godoy et al. (2003) to reduce the amount of crab caught in bottom gill nets. In the previously mentioned study, ropes, named as norsel, were used between the net and lead line by the researchers. However, they reported that modified nets caught more crabs when compared with commercial nets during the first two experiments of their study which consisted of three different experiments. In the same study, the researchers reported that the currents in the region might have caused a so-called "hammock effect" in the nets equipped with the norsels.

The least reduction in the catch amount of the red mullet among the tested nets was found as $13 \%$ with the $25 \mathrm{~cm}$ CTMN. Although this decrease was insignificant, it may cause an economic loss for commercial fishermen. In this experiment, this loss was calculated as $20 \%$ for the $25 \mathrm{~cm} \mathrm{CTMN}$. Similar losses for target species have been reported in other studies with the guarding nets (Bozaoğlu, 2012) and norsel ropes (Godoy et al., 2003; Eayrs \& Salerno, 2008), which are mounted between the nets and the lead line. In addition to economic loss, considering the cost of CTMN (approximately $60 €$ for three nets) and the labour costs provided for the equipping of the CTMN (no charge has been given to the equipment for this work, and the cost of the labour is assumed to be approximately $30 €$ ), it is thought that these nets may not possibly be accepted by the local commercial fleet and fishermen from the area of the present study.

The mean length of the red mullets caught with CTMN was lower than that of the commercial nets (Table 2). The different behaviour between big and small individuals against the obstacle like cloth tarpaulin may have caused this situation.

Although catch amount of the scorpion fish and stargazer species, which are one of the most captured discard species, changed among tested nets, shore crab and the veined rapa whelk were caught in significantly fewer numbers with CTMN. This situation is thought to be caused by the differences in gear structure and behaviour of the species when faced with the CTMN.

Shore crab is one of the most characteristic species for benthic and bento-pelagic macro fauna (Zengin et al., 2017) and a prey for many species (Aydın et al., 2013b). Fishermen do not wish to catch this species because captured individuals make cleaning the trammel net difficult. It was also observed that crabs were exposed to serious injuries during cleaning. Due to the above-mentioned features, the elimination of this species from the net is important for the health of the ecosystem in the region and it is thought that the use of tested CTMN will contribute to this purpose.

It is observed that catches of the veined rapa whelk, which is not marketed in trammel net fisheries, were successfully reduced in the CTMN. They do not constitute a serious problem during cleaning of the nets for fishermen; however, it is observed that more than half of the individuals are below the first maturity length. Therefore, elimination of this species from fishing gears are important in terms of sustainability. Considering the capacity of the boat using these nets in the study area (approx. 150 boats and generally 5 units of net for each boat), we can say that this design serves this purpose even if it is small scale.

It is seen that the most serious problem for the red mullet trammel net fishery is scorpion fish which is the most commonly caught species in the nets for the region. The scorpion fish, which was captured in large quantities (more than target species) where the nets were laid especially in shallow and rocky areas, caused serious labour and time loss during their removal from the nets. It was also observed that it caused damage to the nets and injury and/or numbness of the hands of fishermen. Besides, it was observed that the individuals of this species which were thrown back to the sea during the cleaning of the nets were exposed to serious injuries. Stargazer is the second most important species as a problem for the fishermen in terms of cleaning and damaging the nets. But they are less likely to cause injury to the fishermen compared to the scorpion fish. When the results of this study are examined, it is seen that the tested CTMN are not successful in reducing the amount of catches of these two species which are serious problems for the fisherman.

\section{Conclusion}

Although CTMN has not been significantly successful in reducing the total amount of discards for the study area, discard species such as shore crab and the veined rapa whelk have been successfully reduced. In other fishing areas, where crab species are considered to be an important problem in discard composition, it may be advisable to use $25 \mathrm{~cm}$ CTMN considering the results obtained from this study. Especially in the northeastern Mediterranean in the summer months, a huge amount of captured non-target crab species in the trammel net fishery for prawn species causes extra work for fishermen and damaging of fishing nets. This 
situation caused many fishermen to quit fishing in the area (Bozaoğlu, 2012). In this context, the choice of CTMN modification in this type of fishing areas may be useful. Minimizing the economic loss with future work such as changing the cloth tarpaulin heights can make them more attractive. Besides, considering the reduced functionality of CTMN in areas where bottom current is often available, it will be beneficial to open holes on cloth tarpaulin at frequent intervals to reduce drag easily in the upcoming studies.

\section{Acknowledgements}

We would like to thank the captains and crews of the Orkan 53. Thanks are also extended to Mehmet Şaban Kutay and Muhammet Emanet for their help in the sea trials. The authors would like to thank Bilge Hacımurtazaoğlu and her students for their help in making the modified nets. This study was financed by the Scientific and Technological Research Council of Turkey (TUBITAK 1170024).

\section{References}

Aksu, H., 2006. The effect of using sardon in trammel nets on prevent catching of discorded species. MSc Thesis. Ondokuz Mayıs University, Turkey, 90 pp. (In Turkish).

Anonymous, 2016. The commercial fish catching regulations in seas and inland waters in 2016-2020 fishing period: circular No.2016/35 (in Turkish). Ministry of Food, Agriculture and Livestock, General Directorate of Conservation and Inspection, Ankara, Turkey, 68 pp. (In Turkish).

Aydın, I., Gökçe, G., \& Metin, C. (2013a). Using guarding net to reduce regularly discarded

invertebrates in trammel net fisheries operating on seagrass meadows (Posidonia oceanica) in İzmir Bay (Eastern Aegean Sea). Mediterranean Marine Science, 14 (2), 282291. https://doi.org/10.12681/mms.425.

Aydın, M., Karadurmuş, U. ve Mutlu, \& C. (2013b). Preliminary study on Length-weight relationship and condition factor of Liocarcinus depurator (Linnaeus, 1758) (Brachyura: Portunidae) craps species existing in the Ordu prefecture. The Black Sea Journal of Sciences, 3 (8), 112121.

Bozaoğlu, A.S. (2012). Determination of by-catch and reduction in trammel net fishery for prawn in Mersin Bay. PhD Theses. Mersin University, Turkey, 144 pp. (In Turkish).

Catanese G, Hinz H, Gil MdM, Palmer M, Breen M, Mira A, Pastor E, Grau A, Campos-Candela A, Koleva E, Grau AM, \& Morales-Nin B. (2018). Comparing the catch composition, profitability and discard survival from different trammel net designs targeting common spiny lobster (Palinurus elephas) in a Mediterranean fishery. PeerJ, 6:e4707 https://doi.org/10.7717/peerj.4707
Eayrs, S., \& Salerno, D.J. (2008). Testing raised-webbing gillnets to reduce bycatch of cod while targeting Pollock. Durham, NH: Northeast Consortium, Final report, 28pp.

Eryaşar, A.R. (2017). A Study of the Behaviour of Harbour Crab (Liocarcinus depurator) in Beam Trawl Used in the Rapa Whelk Fishery in Black Sea. Yunus Research Bulletin, 2017 (4), 349-360. https://doi.org/10.17693/yunusae.v17i31121.332657.

FAO. (2018). The State of Mediterranean and Black Sea Fisheries. General Fisheries Commission for the Mediterranean, Rome, $172 \mathrm{pp}$.

Glass, C.W., Wardle, C.S., \& Gosden, S. J. (1993). Behavioural studies of the principles underlying mesh penetration by fish. ICES Marine Science Symposium, 196, 92-97

Godoy, H., Furevik, D., \& Lokkeborg, S. (2003). Reduced Bycatch of Red King Crab (Paralithodes camtschaticus) in the Gillnet Fishery for Cod (Gadus morhua) in Northern Norway. Fisheries Research, 62, 337-384.

Gökçe, G., Bozaoğlu, A.S., Eryaşar, A.R., \& Özbilgin, H. (2016). Discard reduction of trammel nets in the Northeastern Mediterranean prawn fishery. Journal of Applied Ichthyology, 32, 427-431. https://doi.org/10.1111/jai.13015

Kalaycı, F., \& Yeşilçiçek, T. (2014). Influence of season, depth and mesh size on the trammel nets catch composition and discard in the Southern Black Sea, Turkey. Marine Biology Research, 10, 824-832. https://doi.org/10.1080/17451000.2013.853126

Metin, C., Gökçe, G., Aydin, ì., \& Bayramiç, ì. (2009). Bycatch reduction in trammel net fishery for prawn (Melicertus kerathurus) by using guarding net in İmir Bay on Aegean Coast of Turkey. Turkish Journal of Fisheries and Aquatic Sciences, 9 (2), 133-136. https://doi.org/10.4194/trjfas.2009.0202.

R Core Team (2019). R: A language and environment for statistical computing. R Foundation for Statistical Computing, Vienna, Austria. Available online at https://www.R-project.org/.

Sartor, P., Li Veli, D., De Carlo, F., Ligas, A., Massaro, A., Musumeci, C., Sartini, M., Rossetti, I., Sbrana, M., \& Viva, C. (2018). Reducing unwanted catches of trammel nets: experimental results of the "guarding net" in the caramote prawn, Penaeus kerathurus, small-scale fishery of the Ligurian Sea (western Mediterranean). Scientia Marina, 82S1, 131-140. https://doi.org/10.3989/scimar.04765.15B

Tsagarakis, K., Palialexis, A., \& Vassilopoulou, V. (2014). Mediterranean fishery discards: review of the existing knowledge. ICES Journal of Marine Science, 71, 12191234. https://doi.org/10.1093/icesjms/fst074.

Zengin, M, Kaykaç, H, Gümüş, A., \& Akpınar, İ. (2017). Dip Sürütme Ağlarının Bentik Makrofauna Üzerindeki Etkileri: Marmara ve Karadeniz'deki Güncel Durum. Turkish Journal of Aquatic Sciences, 32 (2), 76-95. https://doi.org/10.18864/TJAS201707 